\title{
NY-ESO-1 antigen Paperch Paper NY-ESO-1 antigen expression and immune response are associated with poor prognosis in MAGE-A4-vaccinated patients with esophageal or head/neck squamous cell carcinoma
}

\author{
Shugo Ueda ${ }^{1}$, Yoshihiro Miyahara ${ }^{2}$, Yasuhiro Nagata ${ }^{3}$, Eiichi Sato ${ }^{4}$, Taizo Shiraishi ${ }^{5}$, \\ Naozumi Harada ${ }^{6}$, Hiroaki Ikeda”, Hiroshi Shiku ${ }^{8}$ and Shinichi Kageyama ${ }^{9}$ \\ ${ }^{1}$ Department of Gastroenterological Surgery and Oncology, Kitano Hospital, Kita-ku, Osaka 530-8480, Japan \\ ${ }^{2}$ Department of Personalized Cancer Immunotherapy, Mie University Graduate School of Medicine, Tsu, Mie 514-8507, Japan \\ ${ }^{3}$ Center for Comprehensive Community Care Education, Nagasaki University Graduate School of Biomedical Sciences, \\ Nagasaki 852-8523, Japan \\ ${ }^{4}$ Department of Pathology, Institute of Medical Science, Tokyo Medical University, Shinjuku-ku, Tokyo 160-0023, Japan \\ ${ }^{5}$ Department of Oncologic Pathology, Mie University Graduate School of Medicine, Tsu, Mie 514-8507, Japan \\ ${ }^{6}$ United Immunity, Co., Ltd., Tsu, Mie 514-8507, Japan \\ ${ }^{7}$ Department of Oncology, Nagasaki University Graduate School of Biomedical Sciences, Nagasaki 852-8523, Japan \\ ${ }^{8}$ Departments of Immuno-Gene Therapy and Personalized Cancer Immunotherapy, Mie University Graduate School of \\ Medicine, Tsu, Mie 514-8507, Japan \\ ${ }^{9}$ Department of Immuno-Gene Therapy, Mie University Graduate School of Medicine, Tsu, Mie 514-8507, Japan \\ Correspondence to: Shugo Ueda, email: shu-veda@kitano-hp.or.jp \\ Shinichi Kageyama, email: kageyama@clin.medic.mie-u.ac.jp \\ Keywords: cancer vaccine; MAGE-A4; NY-ESO- 1; immune response; esophageal cancer \\ Received: July 27, $2018 \quad$ Accepted: October 25, $2018 \quad$ Published: November 13, 2018 \\ Copyright: Ueda et al. This is an open-access article distributed under the terms of the Creative Commons Attribution License 3.0 \\ (CC BY 3.0), which permits unrestricted use, distribution, and reproduction in any medium, provided the original author and source \\ are credited.
}

\section{ABSTRACT}

MAGE-A4 antigen is a cancer-testis antigen that is frequently expressed in tumor tissues. Cholesteryl pullulan (CHP) is a novel antigen delivery system for cancer vaccines. This study evaluated the safety, immune responses and clinical outcomes of patients who received a CHP-MAGE-A4 vaccine. Twenty-two patients with advanced or metastatic cancer were enrolled, and were subcutaneously vaccinated with either $100 \mu \mathrm{g}$ or $300 \mu \mathrm{g}$ of CHP-MAGE-A4. Seven and 15 patients, respectively, were repeatedly vaccinated with $100 \mu \mathrm{g}$ or $300 \mu \mathrm{g}$ of CHP-MAGE-A4; patients in both groups received a median of 7 doses. No serious adverse events related to the vaccine were observed. Of 7 patients receiving the $100 \mu$ dose, $2(29 \%)$ showed immune responses, compared with 3 of the $14(21 \%)$ patients who received the $300 \mu \mathrm{g}$ dose. In total, MAGE-A4-specific antibody responses were induced in 5 of 21 (24\%) patients. No differences in survival were seen between patients receiving the $100 \mu \mathrm{g}$ and $300 \mu \mathrm{g}$ doses, or between immune responders and non-responders. Eleven (50\%) patients had pre-existing antibodies to NY-ESO-1. In 16 patients with esophageal or head/ neck squamous cell carcinoma, the survival time was significantly shorter in those who had NY-ESO-1-co-expressing tumors. Patients with high pre-existing antibody responses to NY-ESO-1 displayed worse prognosis than those with no pre-existing response. Therefore, in planning clinical trials of MAGE-A4 vaccine, enrolling NY-ESO1-expressing tumor or not would be a critical issue to be discussed. Combination vaccines of MAGE-A4 and NY-ESO-1 antigens would be one of the strategies to overcome the poor prognosis. 


\section{INTRODUCTION}

The complex of cholesteryl pullulan (CHP) and tumor antigen consists of CHP nanoparticles containing tumor antigen protein, and is a cancer vaccine with a novel antigen delivery system for both MHC class I and class II pathways [1]. Clinical trials have safely and repeatedly administered CHP-HER2 and CHP-NY-ESO-1 vaccines, and both vaccines induced antigen-specific CD8+ and $\mathrm{CD} 4+\mathrm{T}$ cell immunity as well as humoral immune responses [2-4].

Cancer-testis antigens are expressed in the normal testis and placenta, but may be expressed exclusively in tumor tissues, and as such these antigens are considered to be an ideal target for cancer immunotherapy. Among them, the MAGE-family antigens are frequently expressed in tumor tissues; for example, in esophageal cancer, appoximately $50 \%$ of tumors express MAGE-A4, whereas $30 \%$ of tumors express NY-ESO-1 [5]. Thus, MAGE-A4 may be an ideal candidate as a target antigen for cancer vaccines.

Although it has been reported that cancer-testis antigens, including the MAGE-family and NY-ESO-1 antigens, were co-expressed on the same tumor tissues [6], the clinical implication of this fact has not been well explored.

We conducted a dose-escalation trial of CHPMAGE-A4 vaccine with doses of $100 \mu \mathrm{g}$ and $300 \mu \mathrm{g}$ in patients with refractory cancers, including esophageal cancer. We evaluated the safety of the vaccine and the immune responses to both MAGE-A4 and NY-ESO-1 antigens. We found that patients with refractory esophageal or head/neck squamous cell carcinomas that co-expressed MAGE-A4 and NY-ESO-1 had a poorer prognosis than those whose tumors expressed MAGE-A4 but not NYESO-1. Three patients exhibited immune reactions to a non-vaccine antigen during CHP-MAGE-A4 vaccination.

\section{RESULTS}

\section{Patient characteristics and clinical safety (Table 1)}

Eleven patients each were enrolled in a Mie University/Nagasaki Medical Center trial and in a Kitano Hospital trial. Sixteen patients had esophageal cancer, 4 had head/neck cancer, 2 had ovarian cancer, and 1 had duodenal cancer (1 patient had both esophageal and pharyngeal squamous cell carcinoma). All enrolled patients had MAGE-A4-positive refractory/advanced or metastatic tumors. Seventeen patients were male, and 5 were female. The patients were aged 38 to 83 years with a median age of 67 . The number of vaccination doses administered per patient ranged from 4 to 16 , with a median of 7 doses. Fifteen patients developed transient grade 1 skin reactions at the injection sites, which resolved without any treatment. No dose-limiting toxicity was observed. The addition of OK-432 did not increase the rate of adverse events.

\section{Clinical responses and long-term follow-up (Table 1)}

After 6 vaccination cycles, 3 of the 19 evaluable patients showed stable disease (SD), and the other 16 patients showed progressive disease (PD). No patients exhibited tumor regression. The overall survival time was 2.5 to 100.1 months, with a median of 8.4 months. In the cohort receiving the $100 \mu \mathrm{g}$ dose, survival ranged from 2.5 to 100.1 months, with a median of 7.5 months; in the cohort receiving the $300 \mu \mathrm{g}$ dose, survival ranged from 4 to 87.4 months, with a median of 10.3 months. The addition of OK-432 did not improve survival. We did not see correlations between the occurrence of skin reactions at the vaccines sites and the clinical responses or survivals. Six patients with esophageal cancer or head/neck cancer who were vaccinated with $100 \mu \mathrm{g}$ of CHP-MAGE-A4 survived for a median of 7.2 months (range, 2.5 to 8.5). The other 10 patients, who received $300 \mu \mathrm{g}$ of the vaccine, survived for a median of 6.5 months (range, 3.3 to 16.3 ) (Figure 1A). These two durations were not significantly different $(p=0.1320)$.

\section{Expression of NY-ESO-1 antigen in MAGE- A4-expressing tumors (Table 2, Supplementary Table 1)}

Of the 22 patients with MAGE-A4-expressing tumors, 7 had tumors that co-expressed the NYESO-1 antigen. Five of these 7 patients had esophageal carcinomas and 1 each had a duodenal carcinoma and tongue carcinoma. Among the 22 patients, 16 patients had refractory esophageal or head/neck squamous cell carcinoma. Fourteen were assessed for NY-ESO-1 antigen expression using tumor samples. (Supplementary Figure 1). Six had NY-ESO-1-expressing tumors and 8 had NY-ESO-1negative tumors; their median survival times were 4.0 (range, 3.2 to 7.5 ) and 8.6 months (range, 2.5 to 16.0 ), respectively. The survival time was significantly longer in the patients with NY-ESO-1-negative tumors $(p=0.0081)$ (Figure 2A).

\section{Immune responses to MAGE-A4 after CHP- MAGE-A4 vaccinations (Table 2, Table 3)}

Six of the $22(27 \%)$ patients had pre-existing antibodies to MAGE-A4, including 5 with high optical density (OD) (at least twice the cut-off level) and 1 with low OD (below twice the cut-off level) value.

To evaluate the antibody responses after vaccination, serum samples collected at each vaccination were analyzed using a MAGE-A4-specific IgG ELISA. Of the 15 patients who were antibody-negative before vaccination, $4(27 \%)$ became seropositive. One of 6 
Table 1: Clinical characteristics of CHP-MAGE-A4 vaccinated cancer patients and their safeties and survivals after vaccinations

\begin{tabular}{|c|c|c|c|c|c|c|c|c|c|c|c|}
\hline Pt No. & $\begin{array}{l}\text { Code } \\
\text { No. }\end{array}$ & $\begin{array}{l}\text { Age at } \\
\text { entry } \\
/ \text { Sex }\end{array}$ & Disease & $\begin{array}{c}\text { Stage } \\
\text { at } \\
\text { onset }\end{array}$ & Prior therapy & $\begin{array}{l}\text { Lesions at } \\
\text { study entry }\end{array}$ & Dose $(\mu \mathrm{g})$ & $\begin{array}{l}\text { Vaccine } \\
\text { cycle }\end{array}$ & $\begin{array}{l}\text { Related adverse } \\
\text { event (grade) }\end{array}$ & $\begin{array}{c}\text { Tumor } \\
\text { response } \\
\text { (during first } \\
\text { six cylcles) }\end{array}$ & $\begin{array}{c}\text { Survival } \\
\text { time } \\
\text { (month) }\end{array}$ \\
\hline 1 & 766 & $67 / \mathrm{M}$ & $\begin{array}{l}\text { laryngeal squamous } \\
\text { cell cancer }\end{array}$ & IV & surgery, radiotherapy & skin, bone & 100 & 4 & none & PD & 2.5 \\
\hline 2 & 630 & $68 / \mathrm{M}$ & esophageal cancer & III & chemotherapy, radiotherapy & lung, liver & 100 & 10 & none & $\mathrm{PD}$ & 7 \\
\hline 3 & 887 & $82 / \mathrm{F}$ & esophageal cancer & IV & radiotherapy & lymph node & 100 & 6 & skin reaction(I) & $\mathrm{PD}$ & 8.5 \\
\hline 4 & 698 & $48 / \mathrm{F}$ & ovarian cancer & IIc & surgery, chemotherapy & none & 100 & 6 & skin reaction(I) & PD & $100.1^{*}$ \\
\hline 5 & 687 & $68 / \mathrm{M}$ & esophageal cancer & III & chemotherapy, radiotherapy & $\begin{array}{l}\text { esophagus, } \\
\text { lymph node }\end{array}$ & 300 & 4 & none & PD & 8.8 \\
\hline 6 & 998 & $62 / \mathrm{M}$ & esophageal cancer & IV & chemotherapy, radiotherapy & none & 300 & 15 & skin reaction(I) & not evaluable & $68.3^{*}$ \\
\hline 7 & 1147 & $64 / \mathrm{F}$ & esophageal cancer & IV & surgery & lymph node & 300 & 11 & skin reaction(I) & SD & 10.3 \\
\hline 8 & 1358 & $38 / \mathrm{F}$ & ovarian cancer & IIII & surgery, chemotherapy & none & 300 & 12 & none & not evaluable & $87.4^{*}$ \\
\hline 9 & 1188 & $60 / \mathrm{M}$ & esophageal cancer & III & chemotherapy, radiotherapy & none & 300 & 10 & none & not evaluable & $84.2^{*}$ \\
\hline 10 & 704 & $69 / \mathrm{M}$ & esophageal cancer & IV & chemotherapy, radiotherapy & liver & 300 & 6 & none & $\mathrm{PD}$ & 4.1 \\
\hline 11 & NMC001 & $76 / \mathrm{M}$ & esophageal cancer & II & chemothrapy, radiotherapy & esophagus & 300 & 6 & skin reaction(I) & $\mathrm{PD}$ & 16.3 \\
\hline 12 & KIT-5 & $69 / \mathrm{M}$ & esophageal cancer & IV & $\begin{array}{c}\text { chemotherapy, radiotherapy, } \\
\text { immunotherapy }\end{array}$ & $\begin{array}{l}\text { lung, lymph } \\
\text { node }\end{array}$ & 100 & 14 & skin reaction(I) & PD & 7.5 \\
\hline 13 & KIT-8 & $67 / \mathrm{M}$ & esophageal cancer & IV & $\begin{array}{l}\text { chemotherapy, } \\
\text { radiotherapy }\end{array}$ & $\begin{array}{c}\text { primary } \\
\text { tumor, lymph } \\
\text { node }\end{array}$ & 100 & 7 & skin reaction(I) & PD & 3.2 \\
\hline 14 & KIT-9 & $56 / \mathrm{M}$ & esophageal cancer & IIB & $\begin{array}{l}\text { surgery, } \\
\text { chemotherapy, } \\
\text { radiotherapy }\end{array}$ & $\begin{array}{l}\text { lung, lymph } \\
\text { node }\end{array}$ & $\begin{array}{c}100, \\
(->300)\end{array}$ & 16 & skin reaction(I) & PD & 7.6 \\
\hline 15 & KIT-10 & $76 / \mathrm{F}$ & esophageal cancer & IIIC & $\begin{array}{l}\text { chemotherapy, } \\
\text { radiotherapy }\end{array}$ & $\begin{array}{c}\text { primary } \\
\text { tumor, } \\
\text { lymph node }\end{array}$ & 300 & 7 & skin reaction(I) & PD & 4.3 \\
\hline 16 & KIT-11 & $64 / \mathrm{M}$ & esophageal cancer & IV & $\begin{array}{l}\text { chemotherapy, } \\
\text { radiotherapy }\end{array}$ & lymph node & 300 & 7 & skin reaction(I) & PD & 3.4 \\
\hline 17 & KIT-12 & $83 / \mathrm{M}$ & $\begin{array}{c}\text { esophageal and } \\
\text { pharyngeal cancer }\end{array}$ & IVA & $\begin{array}{l}\text { chemotherapy, } \\
\text { radiotherapy }\end{array}$ & $\begin{array}{c}\text { primary } \\
\text { tumor }\end{array}$ & 300 & 4 & none & PD & 3.3 \\
\hline 18 & KIT-13 & $69 / \mathrm{M}$ & duodenal cancer & IIIA & $\begin{array}{l}\text { surgery, } \\
\text { chemotherapy }\end{array}$ & $\begin{array}{l}\text { lymph node, } \\
\text { lung, liver }\end{array}$ & 300 & 14 & skin reaction(I) & PD & 8.2 \\
\hline 19 & KIT-14 & $72 / \mathrm{M}$ & esophageal cancer & IIB & $\begin{array}{l}\text { chemotherapy, } \\
\text { radiotherapy }\end{array}$ & $\begin{array}{l}\text { primary } \\
\text { tumor }\end{array}$ & 300 & 7 & skin reaction(I) & PD & 10.9 \\
\hline 20 & KIT-15 & $66 / \mathrm{M}$ & $\begin{array}{l}\text { tongue squamous } \\
\text { cell cancer }\end{array}$ & IVA & $\begin{array}{l}\text { surgery, } \\
\text { chemotherapy, } \\
\text { radiotherapy }\end{array}$ & $\begin{array}{c}\text { pleural } \\
\text { dissemination }\end{array}$ & $300+$ OK 432 & 6 & skin reaction(I) & PD & 4 \\
\hline 21 & KIT-16 & $63 / \mathrm{M}$ & parotid cancer & IVA & surgery & $\begin{array}{c}\text { pleural } \\
\text { dissemination }\end{array}$ & $300+\mathrm{OK} 432$ & 9 & skin reaction(I) & SD & 36.6 \\
\hline 22 & KIT-17 & $66 / \mathrm{M}$ & esophageal cancer & IV & $\begin{array}{l}\text { chemotherapy, } \\
\text { radiotherapy }\end{array}$ & lymph node & $300+\mathrm{OK} 432$ & 8 & skin reaction(I) & SD & 16 \\
\hline
\end{tabular}

(17\%) initially antibody-positive patients had augmented antibody responses. In total, 5 of $21(24 \%)$ patients exhibited immune responses. In the 7 patients receiving the $100 \mu \mathrm{g}$ dose, $2(29 \%)$ showed an immune response, whereas 3 of the $14(21 \%)$ patients receiving the $300 \mu \mathrm{g}$ dose exhibited a response. The 4 patients with esophageal or head/neck squamous cell carcinoma who exhibited an immune response to MAGE-A4 survived for a median of 3.3 months (range, 2.5 to 10.9). The other 11 patients with no immune response survived for a median of 7.6 months (range, 3.3 to 16.3) (Figure 1B). These survival times were not significantly different $(p=0.2165)$.

\section{Spreading immune response to NY-ESO-1 after CHP-MAGE-A4 vaccinations}

As shown in Tables 2 and 3, 11 of the $22(50 \%)$ patients had pre-existing antibodies to NY-ESO-1, including 6 with high OD values. In 7 patients whose tumors expressed both MAGE-A4 and NY-ESO-1 antigens, $6(86 \%)$ had pre-existing antibodies to NY-ESO-1.

Of the 21 patients overall, 3 exhibited immune responses to NY-ESO-1 during CHP-MAGE-A4 vaccination, and all 3 of these patients had pre-existing antibody responses to NY-ESO-1. Eleven patients were initially seropositive for NY-ESO-1, and 27\% (3/11) of these showed an immune response to this antigen (Tables 2 and 3, Figure 3A). The 3 patients (Nos. 12, 14, and 20) who developed spreading immune responses to NY-ESO-1 did not exhibit an immune response to MAGE-A4 (Table 2, Figure 3A). In contrast, none of the patients without pre-existing immunity to NY-ESO-1 showed an immune response to NY-ESO-1 (Table 2, Figure 3B). Of the 13 patients whose tumors did not express the NY-ESO- 1 antigen, 1 patient showed an antibody response to NY-ESO-1 (Table 2, Figure 3C). Of 7 
patients whose tumors expressed both antigens, 2 showed antibody responses to NY-ESO-1 (Table 2, Figure 3D). One esophageal cancer patient, No. 12 or code No. KIT-5, was vaccinated with NY-ESO-1 protein in a prior clinical trial [4]. At the beginning of that trial the patient did not have pre-existing antibodies to the NY-ESO-1 antigen, and the response was induced over the course of the vaccinations (Figure 4A). Twelve months after the CHPNY-ESO-1 vaccinations, the patient's antibody level had decreased to a marginal level of 0.29 OD (Table 2, Figure 4B). The patient did have pre-existing antibodies (1.91
OD) to MAGE-A4 antigen at the start of the current trial, and received 14 cycles of the CHP-MAGE-A4 vaccine. Interestingly, no augmentation of immunity to MAGE-A4 was seen, and instead, a definite antibody response to NY-ESO-1 was observed over the course of the CHPMAGE-A4 vaccinations (Figure 4B).

The median survival time in the 5 patients with high levels of pre-existing NY-ESO-1 antibodies was 3.3 months (range, 2.5 to 7.0 ), while the 11 patients in whom these antibodies were either absent or occurred at low levels survived a median of 8.5 months (range, 3.4 to

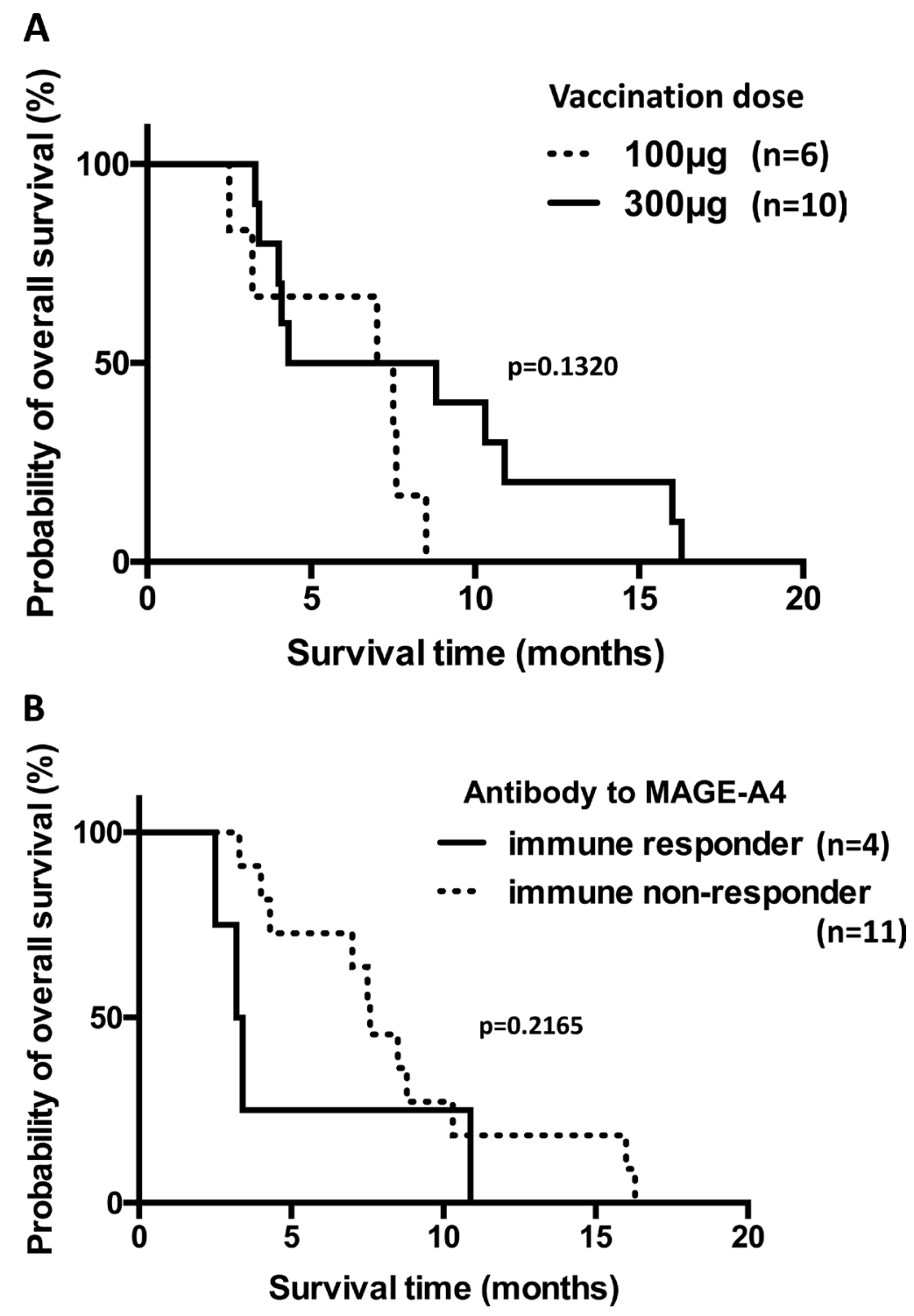

Figure 1: Overall survival of patients with refractory esophageal or head/neck squamous cell carcinoma who received the CHP-MAGE-A4 vaccine. (A) Kaplan-Meier survival curves of 16 patients with refractory esophageal or head/neck squamous cell carcinoma who were vaccinated with CHP-MAGE-A4. Six patients were given a $100 \mu \mathrm{g}$ vaccine dose, while the other 10 patients were given the $300 \mu \mathrm{g}$ dose. The survival times are not statistically different $(p=0.1320)$. (B) 15 patients with refractory esophageal or head/ neck squamous cell carcinoma, were evaluated for the immune responses to MAGE-A4. Patient No. 10 (code No. 704) was excluded, in whom the antibody datum at post-vaccine was not available. Four patients with esophageal or head/neck squamous carcinoma exhibited immune responses to MAGE-A4. The other 11 patients did not have such responses. The survival times are not statistically different $(p=0.2165)$. 
Table 2: Expression of MAGE-A4 and NY-ESO-1 antigens on tumor tissues and humoral immune responses after MAGE-A4 vaccinations

\begin{tabular}{|c|c|c|c|c|c|c|c|c|c|c|c|}
\hline \multirow[b]{2}{*}{ Pt No. } & \multirow[b]{2}{*}{ Code No. } & \multirow{2}{*}{$\begin{array}{c}\text { MAGE-A4 expression } \\
\text { (\% in a MCV-1/IHC } \\
\text { sample) }\end{array}$} & \multicolumn{4}{|c|}{ Humoral immune response to MAGE-A4 } & \multirow{2}{*}{$\begin{array}{l}\text { NY-ESO-1 } \\
\text { expression (\% in a } \\
\text { IHC sample) }\end{array}$} & \multicolumn{4}{|c|}{ Humoral immune response to NY-ESO-1 } \\
\hline & & & $\begin{array}{c}\text { Baseline } \\
\text { status }\end{array}$ & $\begin{array}{l}\text { OD value } \\
\text { (pre) }\end{array}$ & $\begin{array}{l}\text { OD value } \\
\text { (post) }\end{array}$ & Response & & $\begin{array}{c}\text { Baseline } \\
\text { status }\end{array}$ & OD value (pre) & OD value (post) & Response \\
\hline 1 & 766 & + & - & 0.17 & 0.56 & responded & - & + & 1.30 & 1.23 & none \\
\hline 2 & 630 & + & - & 0.18 & 0.13 & none & + & + & 0.67 & 0.78 & none \\
\hline 3 & 887 & $+(40 \%)$ & + & 1.74 & 1.73 & none & - & - & 0.12 & 0.14 & none \\
\hline 4 & 698 & + & - & 0.10 & 0.10 & none & - & - & 0.09 & 0.08 & none \\
\hline 5 & 687 & + & + & 0.60 & 0.97 & none & - & - & 0.08 & 0.10 & none \\
\hline 6 & 998 & + & + & 0.78 & 0.64 & none & - & + & 0.33 & 0.35 & none \\
\hline 7 & 1147 & + & - & 0.21 & 0.31 & none & - & - & 0.20 & 0.22 & none \\
\hline 8 & 1358 & + & - & 0.16 & 0.28 & none & - & - & 0.18 & 0.18 & none \\
\hline 9 & 1188 & + & - & 0.17 & 0.17 & none & - & - & 0.17 & 0.15 & none \\
\hline 10 & 704 & + & - & 0.13 & NA & NA & + & - & 0.08 & NA & NA \\
\hline 11 & NMC001 & + & + & 0.65 & 0.82 & none & NA & - & 0.14 & 0.15 & none \\
\hline 12 & KIT-5 & $+(90 \%)$ & + & 1.91 & 2.00 & none & $+(5 \%)$ & + & 0.29 & 1.66 & augmented \\
\hline 13 & KIT-8 & $+(30 \%)$ & + & 0.65 & 1.57 & augmented & $+(30 \%)$ & + & 1.71 & 1.82 & none \\
\hline 14 & KIT-9 & + & - & 0.21 & 0.19 & none & - & + & 0.32 & 1.78 & augmented \\
\hline 15 & KIT-10 & + & - & 0.08 & 0.07 & none & - & - & 0.09 & 0.07 & none \\
\hline 16 & KIT-11 & + & - & 0.16 & 0.42 & responded & NA & - & 0.12 & 0.11 & none \\
\hline 17 & KIT-12 & + & - & 0.20 & 0.20 & none & $+(30 \%)$ & + & 0.69 & 0.79 & none \\
\hline 18 & KIT-13 & $+\left(2 \%{ }^{*}\right)$ & - & 0.26 & 0.88 & responded & $+(70 \%)$ & + & 1.73 & 1.78 & none \\
\hline 19 & KIT-14 & + & - & 0.09 & 0.70 & responded & - & - & 0.07 & 0.06 & none \\
\hline 20 & KIT-15 & $+(30 \%)$ & - & 0.23 & 0.31 & none & $+(5 \%)$ & + & 0.66 & 1.45 & augmented \\
\hline 21 & KIT-16 & + & - & 0.10 & 0.16 & none & - & + & 0.27 & 0.44 & none \\
\hline 22 & KIT-17 & + & - & 0.17 & 0.17 & none & - & + & 0.36 & 0.27 & none \\
\hline
\end{tabular}

"focally stained.

Cut-off levels for MAGE-A4 and NY-ESO-1 are 0.32 and 0.27 , respectively.

Two-fold or more increase from the baseline level in patients with pre-existing antibodies are shown as augmented.

Abbreviations: IHC, immunohistochemistry, NA, not available.

16.3). Survival time was significantly longer in NY-ESO-1 seronegative patients, including those with low titers of the antibody, than in those with high levels of pre-existing NYESO-1 antibodies $(p=0.0007)$ (Supplementary Figure 1, Figure 2B).

\section{Seromics: array profiling assay}

Seven patients provided serum samples both before and after vaccine administration, and sera were assayed using ProtoArray microarrays. In Figure 5A and 5B, the response patterns to 77 cancer-testis antigens (Table 4) are shown for both time periods. While different patients responded to different antigens, each individual patient responded to the same antigens both before and after vaccination. This indicates that patients had antibodies to multiple antigens prior to CHP-MAGE-A4 vaccinations and that spreading immune reactions arose from these preexisting responses.

\section{DISCUSSION}

In this phase I clinical trial, we evaluated the safety and immunogenicity of the CHP-MAGE-A4 cancer vaccine, and found that the vaccine was safe and that immune responses were induced in $24 \%$ of 21 patients with advanced cancer. The $100 \mu \mathrm{g}$ vaccine dose resulted in immune responses in $29 \%$ of patients, compared with $21 \%$ for the $300 \mu \mathrm{g}$ dose, indicating no dose-dependency. We previously reported that the NY-ESO-1 protein vaccine complexed with CHP showed dose-dependent immune responses [7]. Regarding the current CHPMAGE-A4 trial, it is unclear if the low rate of immune responses indicates that a higher dose of MAGE-A4 should be used in the vaccine, or if the MAGE-A4 protein is not sufficiently immunogenic. A future phase II dose-escalation trial should be conducted to determine a recommended dose.

Of the 22 patients in this study, $27 \%$ had preexisting antibody responses to the MAGE-A4 antigen. This rate is similar to other cancer-testis antigens, such as NY-ESO-1, and indicates that the MAGE-A4 antigen is immunogenic enough to induce immune reactions in hosts bearing MAGE-A4-expressing tumors [8]. We also found that 7 of $20(35 \%)$ cases of MAGE-A4-expressing tumors simultaneously expressed NY-ESO-1. Six of the $7(86 \%)$ patients who expressed both antigens had preexisting immunity to NY-ESO-1 as well. This indicates 
that expression of multiple cancer-testis antigens might create high immunogenic activity in cancer-bearing hosts.

We observed antigen spreading to NY-ESO-1 during CHP-MAGE-A4 vaccinations in three (14\%) patients, all of whom had pre-existing NY-ESO-1 immunity. In contrast, no spreading reactions were induced in patients who did not have these pre-existing antibodies. To examine if pre-existing immunity is required for spreading immune responses, we used ProtoArray microarrays to analyze patient sera obtained before and after vaccine administration. As shown in Figure 5, CHP-MAGE-A4 vaccination induced the response against pre-existing antigen rather than de novo immune response. CHP and/ or OK-432 may contribute to augment the subliminal response. Also, it is possible that some of these proteins in Table 4 may attenuate immune regulation in tumor micro-environment. To confirm the mechanism of antigen spreading, accumulation of more data would be necessary. In a previous report that investigated antigen spreading in CHP-NY-ESO-1-vaccinated patients, 8 of 9 patients with immune responses to NY-ESO-1 also responded to antigens other than NY-ESO-1, including MAGE-A4 [9]. Since these patients had tumors that expressed one or more antigens other than NY-ESO-1, we can conclude that antigen spreading may often occur over the course of vaccination in patients whose tumors express multiple antigens.

The clinical significance of such spreading immune reactions has not been well investigated. However, one study demonstrated that $\mathrm{T}$ cells that recognized a non-vaccine antigen, a neo-antigen in this case, was a primary contributor to tumor regression in a
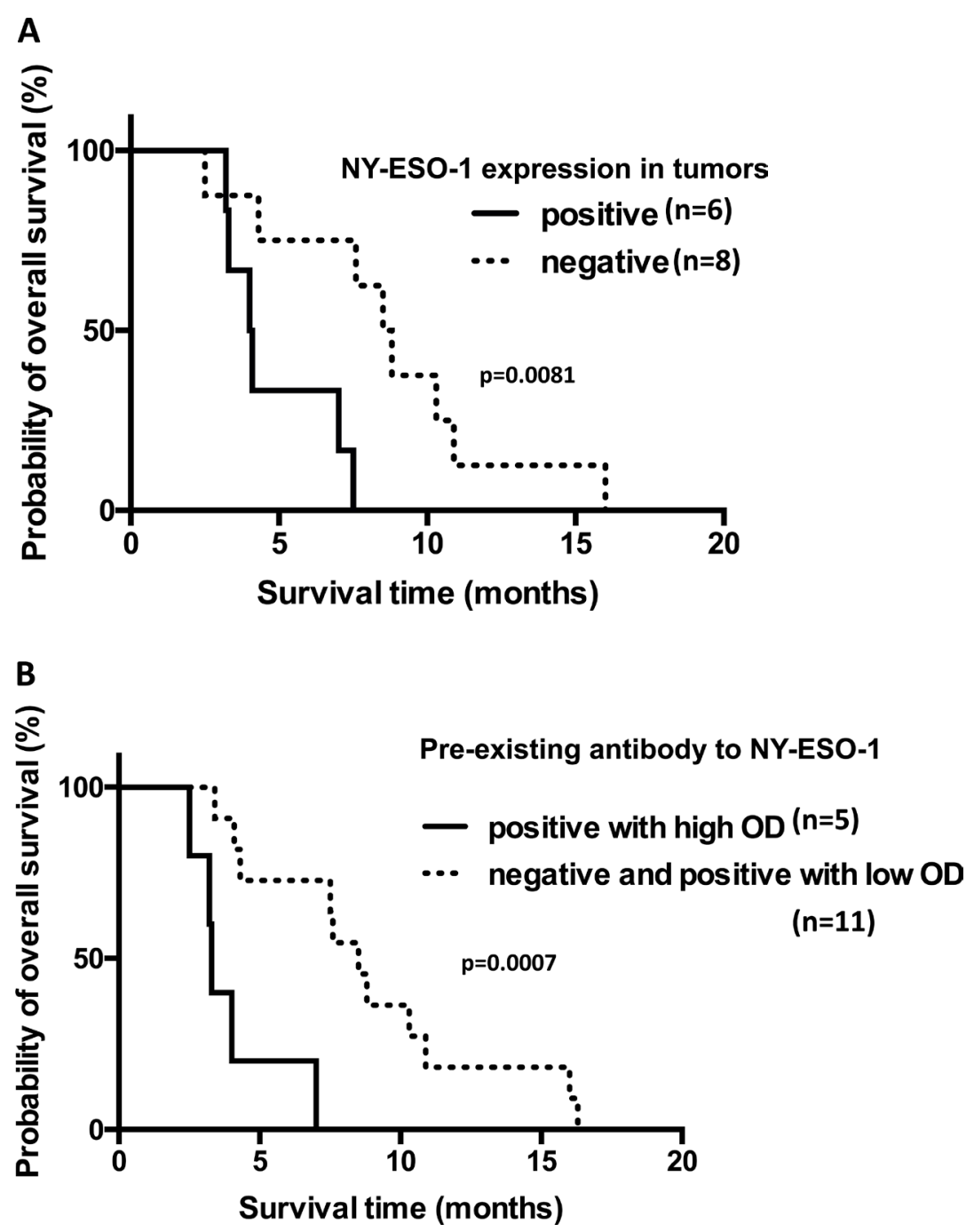

Figure 2: Overall survival of patients with refractory esophageal or head/neck squamous carcinoma who co-expressed NY-ESO-1 or had pre-existing immunity to NY-ESO-1. (A) Kaplan-Meier survival curves of 14 patients with refractory esophageal or head/neck squamous cell carcinoma who received the CHP-MAGE-A4 vaccine. Six patients had NY-ESO-1-expressing tumors and 8 had NY-ESO-1-negative tumors. Survival time was significantly longer in esophageal or head/neck squamous carcinoma patients with NY-ESO-1-negative tumors than in those with NY-ESO-1-positive tumors $(p=0.0081)$. (B) Overall survival of patients with or without pre-existing anti-NY-ESO-1 antibody. Survival time was significantly shorter in esophageal or head/neck squamous carcinoma patients with high levels of pre-existing antibody than those without it, including those with low titers of the antibody $(p=0.0007)$. 
Table 3: Immune responses to MAGE-A4 and NY-ESO-1 in 21 patients vaccinated with CHP-MAGE-A4

\begin{tabular}{|c|c|c|c|}
\hline & Number of patients & $\begin{array}{c}\text { Immune responder to } \\
\text { MAGE-A4 }\end{array}$ & Response rate $(\%)$ \\
\hline $\begin{array}{l}\text { negatives of pre-existing antibody to } \\
\text { MAGE-A4 }\end{array}$ & $15^{*}$ & 4 & 27 \\
\hline $\begin{array}{l}\text { positives of pre-existing antibody to } \\
\text { MAGE-A4 }\end{array}$ & 6 & 1 & 17 \\
\hline vaccine of $100 \mu \mathrm{g}$ dose & 7 & 2 & 29 \\
\hline \multirow[t]{2}{*}{ vaccine of $300 \mu \mathrm{g}$ dose } & $14^{*}$ & 3 & 21 \\
\hline & Number of patients & $\begin{array}{c}\text { Immune responder to } \\
\text { NY-ESO-1 }\end{array}$ & Response rate $(\%)$ \\
\hline $\begin{array}{l}\text { positives of pre-existing antibody to } \\
\text { NY-ESO-1 }\end{array}$ & 11 & 3 & 27 \\
\hline $\begin{array}{l}\text { negatives of pre-existing antibody to } \\
\text { NY-ESO-1 }\end{array}$ & $10^{*}$ & 0 & 0 \\
\hline
\end{tabular}

*patient No. 10 (code No. 704) was excluded, in whom the antibody data at post-vaccine was not available.

MAGE-vaccinated melanoma patient [10]. In the current trial, of the 16 patients with either refractory esophageal cancer $(n=14)$ or head/neck squamous cell carcinoma $(n=2)$, the 3 patients who demonstrated antigen spreading survived for a median of 7.5 months, while the 12 patients without spreading survived for 7.7 months. These times were similar. Notably, one patient, KIT-5, had a long survival for more than 3 years from the onset of esophageal cancer, and marked immune spreading to NY-ESO-1 was induced during CHP-MAGE-A4 vaccination. Given these findings, further studies should investigate to clarify the association of antigen spreading and survival impacts in vaccinated esophageal cancer patients.

It has been reported that NY-ESO-1 antibody may be related to tumor burden in patients with NYESO-1-expressing tumors. One study found that $31 \%$ of esophageal cancer patients had NY-ESO-1 autoantibodies, and the positive rate increased with tumor stage progression [8]. Another study demonstrated that NY-ESO-1 antibody positivity increased with disease progression in gastric cancer patients, and that antibody levels decreased with surgical resection and chemotherapies [11]. The spreading reaction to NY-ESO-1 in the 3 esophageal cancer patients in this study could be explained by increasing tumor burden, as all 3 patients had distant metastases at study entry and all showed tumor progression after vaccination.

For the first time, we demonstrated that patients with refractory esophageal or head/neck squamous cell carcinoma that co-expressed MAGE-A4 and NY-ESO-1 had significantly worse prognosis than patients with tumors expressing MAGE-A4 alone. Previous studies in several cancers found that NY-ESO-1 expression had varying effects on prognosis. With regard to esophageal cancer, one study suggested that NY-ESO-1 expression was associated with favorable overall survival [12].
Akcakanat et al. investigated 213 esophageal cancer patients and demonstrated no impact of NY-ESO-1 expression on either progression-free survival or overall survival [6]. The latter study enrolled 111 MAGEA-expressing esophageal cancer patients, of whom $32(28.8 \%)$ co-expressed NY-ESO-1, and found that MAGE-A and NY-ESO-1 co-expression did not affect prognosis. These results are inconsistent with our findings and might reflect differences in the clinical status of the investigated cohorts; our study included refractory tumors, while the study by Akcakanat et al. investigated newly diagnosed cases. A large study that examined ovarian tumor samples from 1,002 patients showed significantly worse clinical outcomes in patients whose tumor tissues expressed NY-ESO-1 [13], and found that if these patients enrolled in cancer vaccine trials, their overall survival was prolonged. In our trial, despite the CHP-MAGE-A4 vaccine, patients with NY-ESO-1-expressing tumors had significantly shorter survival than those without NYESO-1 expression. One explanation would be an adverse influence of NY-ESO-1 antigen expression in tumors, and it is not known if NY-ESO-1 expression is related the disease aggressiveness, or it is associated with disease progression. Expression of MAGE-A4 has not been known to be related to disease prognosis. However, in our study the biological role of co-expression of the two antigens is still unknown. Thus, the MAGE-A4 vaccine should not have been administered to the group with NYESO-1 expression, and instead a NY-ESO-1 vaccine might be chosen to mitigate the worse prognosis. The other strategy would be combination vaccine of MAGE-A4 and NY-ESO-1 antigens, which could overcome the worse prognosis of the two-antigen expressing esophageal or head/neck cancer patients in the future clinical trial.

Two other independently conducted clinical trials of the CHP-MAGE-A4 vaccine have been reported to date $[14,15]$. Saito et al. reported that 4 of $20(20 \%)$ 
patients receiving a $300 \mu \mathrm{g}$ dose developed antibody responses, and these patients had significantly longer survival than the patients with no immune responses. In contrast, in our study we saw no difference in survival between patients with and without immune responses.
Other factors may have influenced the clinical outcomes in our study population, although our rate of immune reaction was slightly higher. Miyauchi et al. reported that 6 patients $(50 \%)$ developed spreading immune reactions to NY-ESO-1 and that the spread to the other antigens

A Patients with pre-existing IgG to NY-ESO-1
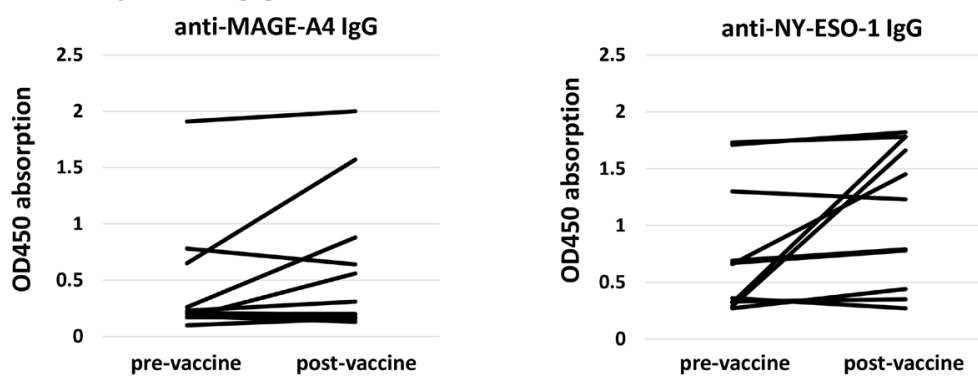

B Patients without pre-existing IgG to NY-ESO-1
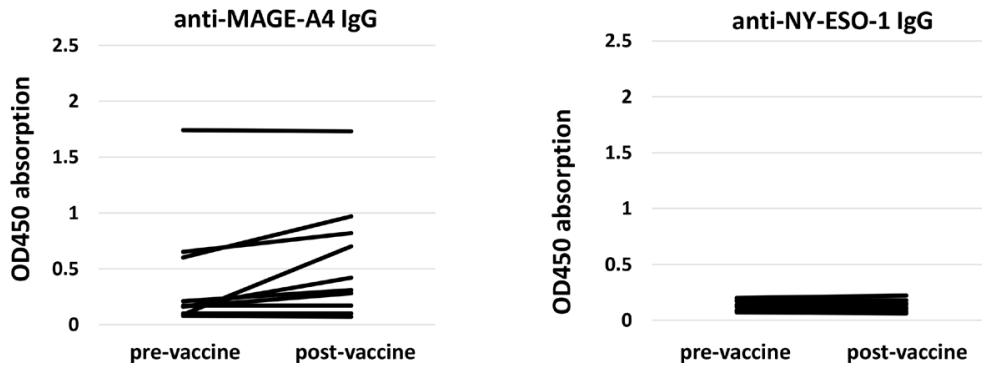

C Patients without NY-ESO-1-expressing tumors
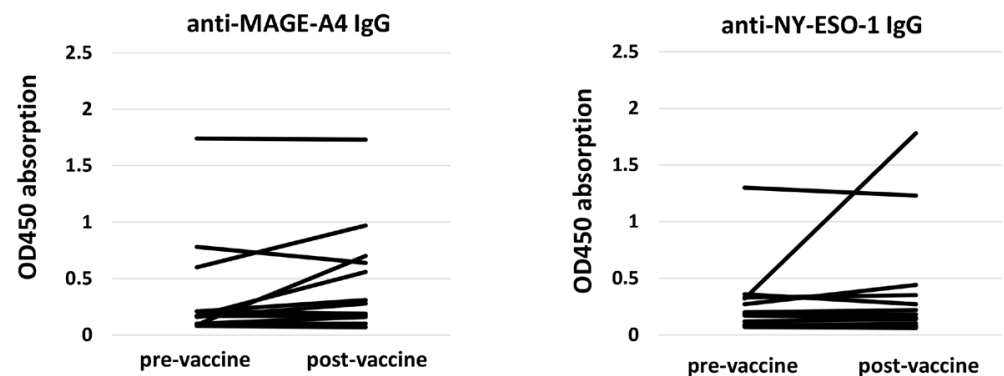

D Patients with NY-ESO-1-expressing tumors
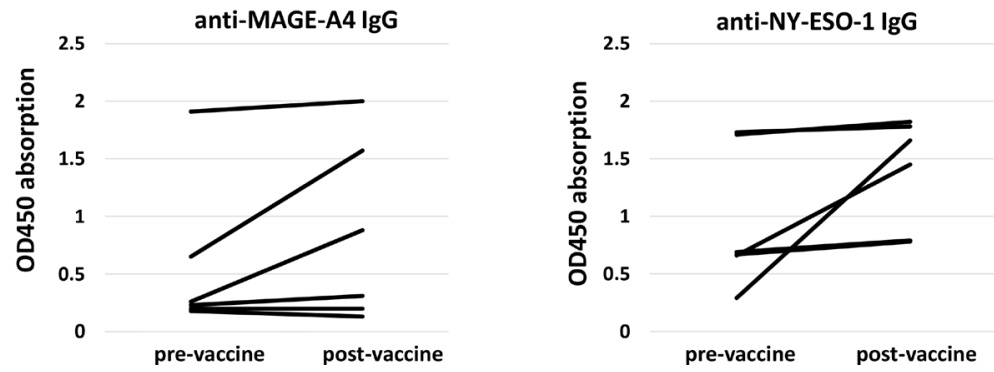

Figure 3: Antibody responses after CHP-MAGE-A4 vaccinations. (A) Left panel shows IgG responses measured by ELISA assay to MAGE-A4 protein in patients who had pre-existing IgG to NY-ESO-1 antigen $(n=11)$. Right panel shows IgG responses to NYESO-1 protein in the same patients. (B) Left panel shows IgG responses measured by ELISA assay to MAGE-A4 protein in patients who did not have pre-existing IgG to NY-ESO-1 antigen $(n=10)$. Right panel shows IgG responses to NY-ESO-1 protein in the same patients. (C) Left panel shows IgG responses to MAGE-A4 protein in patients whose tumors did not express NY-ESO-1 antigen $(n=13)$. Right panel shows IgG responses to NY-ESO-1 protein in the same patients. (D) Left panel shows IgG responses to MAGE-A4 protein in patients whose tumors expressed NY-ESO-1 antigen $(n=6)$. Right panel shows IgG responses to NY-ESO-1 protein in the same patients. 
had no relation to clinical outcomes. Their findings are compatible with our own.

In conclusion, the CHP-MAGE-A4 vaccine was well tolerated in patients with refractory cancer, $24 \%$ of whom exhibited immune responses to MAGE-A4 following the $100 \mu \mathrm{g}$ or $300 \mu \mathrm{g}$ vaccine doses. Also, we found that patients with esophageal or head/neck squamous cell carcinoma often demonstrated co-expression of MAGE-A4 and NY-ESO-1 in their tumors, and this was associated with worse prognosis, especially in those who had pre-existing antibodies to NY-ESO-1. Antigen spreading occurred in patients who had already been sensitized with primary reactions to other antigens when they were vaccinated with MAGE-A4 cancer vaccine. Therefore, in planning clinical trials of MAGE-A4 vaccine, enrolling NY-ESO-1-expressing tumor or not would be a critical issue to be discussed. Combination vaccines of MAGE-A4 and NY-ESO-1 antigens would be one of the strategies to overcome the poor prognosis.

\section{PATIENTS AND METHODS}

\section{Preparation of the CHP-MAGE-A4 complex vaccine}

The CHP-MAGE-A4 complex vaccine was provided by ImmunoFrontier, Inc. (Tokyo, Japan). Fulllength MAGE-A4 cDNA was cloned into the $\mathrm{pET}$ vector and introduced into Escherichia coli cells. The produced protein was recovered and highly purified using a

\section{A}

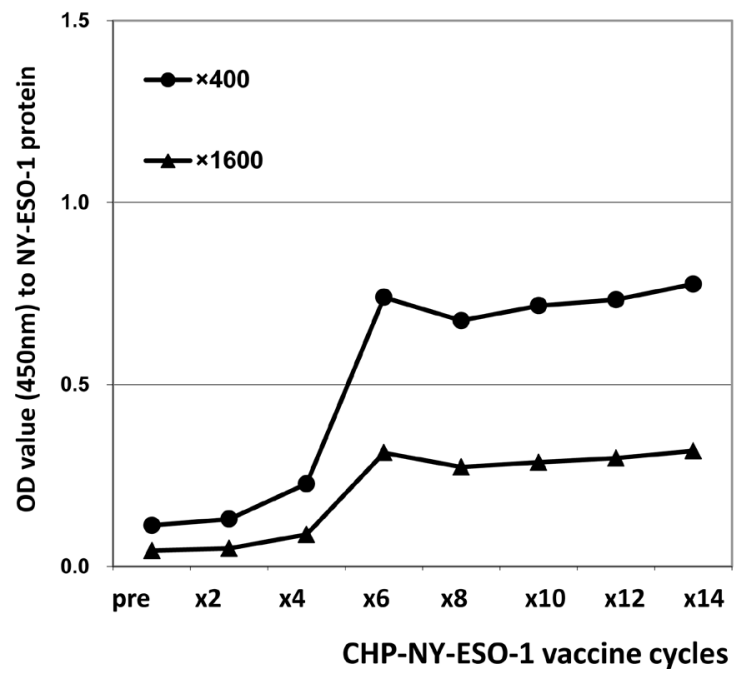

combination of chromatographic techniques, including metal-chelating affinity chromatography, anion exchange chromatography, size exclusion chromatography, and hydroxyapatite chromatography. CHP was synthesized by a chemical reaction between pullulan (average molecular weight: $100 \mathrm{kDa}$ ) and cholesterol isocyanate in pyridine/dimethyl sulfoxide solution (NOF Corporation, Tokyo, Japan). After purification by extraction and precipitation, the resultant CHP was emulsified in water, then freeze dried. When dissolved in water or buffers, CHP spontaneously forms nanoparticles $(20-50 \mathrm{~nm})$. The hydrophobic domains of cholesterol on the inside of these nanoparticles associate with the hydrophobic regions of the MAGE-A4 protein, forming a stable complex in solution. This complex of protein and CHP was used as the CHP-MAGE-A4 vaccine. All processes were performed following current Good Manufacturing Practices. The toxicity of the drug product was assessed using animal models, and stability was monitored during the clinical trial using representative samples of the investigational drug product.

\section{Study design}

Two phase I open-label clinical trials were conducted independently, one at Mie University Hospital and Nagasaki Medical Center, and the other at Kitano Hospital. Eleven patients, each with refractory tumor expressing MAGE-A4, were enrolled in each trial: patient numbers $1-11$ and 12-22, respectively (Table 1).

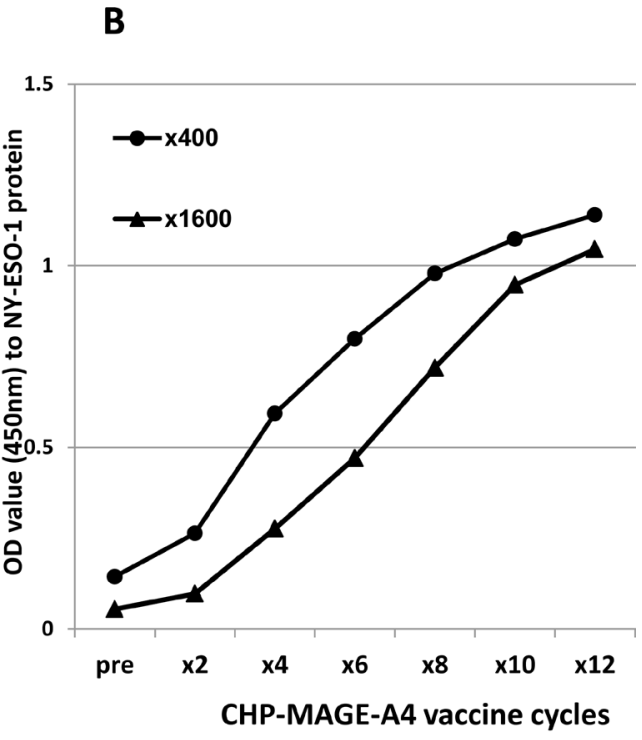

Figure 4: Antibody responses to NY-ESO-1 in a patient who received prior vaccine with NY-ESO-1 protein and the present vaccine with MAGE-A4. (A) IgG responses measured by ELISA assay to NY-ESO-1 protein in patient No.12 (KIT-5). The serum was diluted by 400 or 1,600 and assayed by ELISA. No antibody response existed before the vaccination. Six cycles of CHP-NY-ESO-1 vaccine at $100 \mu \mathrm{g}$ per dose induced antibody responses. The intensities plateaued following the repeated vaccinations. (B) IgG responses to NY-ESO-1 protein. The NY-ESO-1-antibody response disappeared before vaccination. Four cycles of CHP-MAGE-A4 vaccine at $100 \mu \mathrm{g}$ per dose induced antibody responses to NY-ESO-1. The intensities increased with repeated vaccinations. 
The results were analyzed together, because these 2 clinical trials were conducted using the same vaccine for the same assessment of MAGE-A4 tumor expression. Primary objectives of each study were safety, specifically maximum tolerable dose, dose-limiting toxicity, and profiles of adverse events, and efficacy, specifically MAGE-A4-specific immune responses. The secondary objective of each study was clinical efficacy, specifically tumor responses and overall survival.
Patients were eligible for entry if they had a performance status (PS) of 0,1 , or 2, were at least 20 years old, had a life expectancy of 4 months or more, and did not have impaired organ function. Patients were ineligible if they were positive for HIV antibody; had multiple active cancers, autoimmune disease, serious allergic history, or active brain metastasis; or received systemic steroids or immunosuppressive therapy within 4 weeks prior to the start of this study.

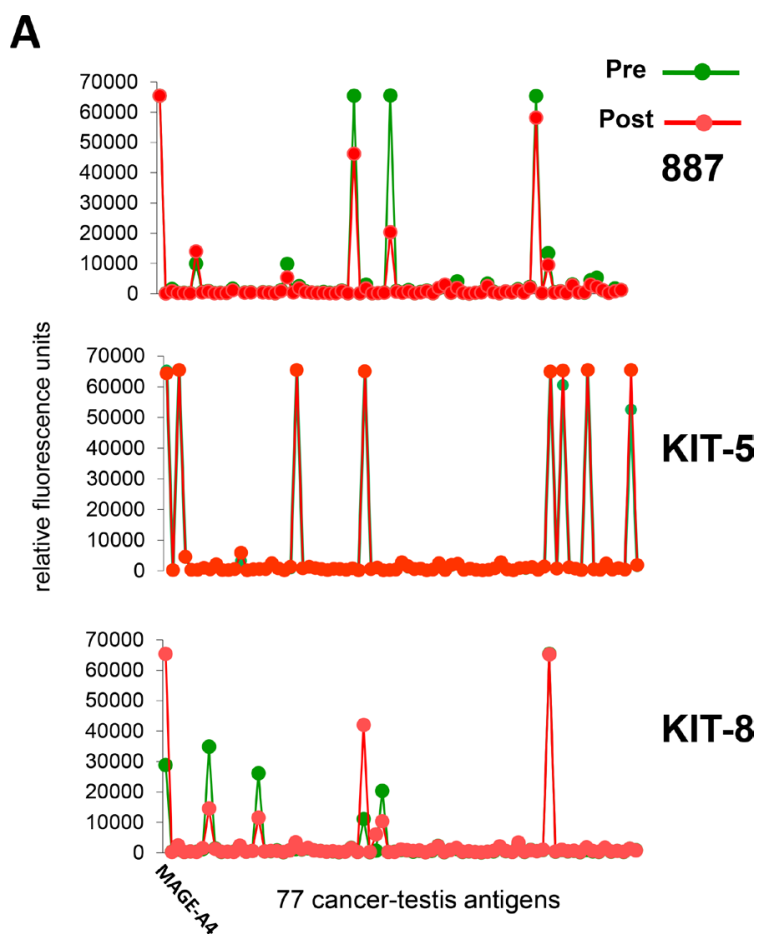

B

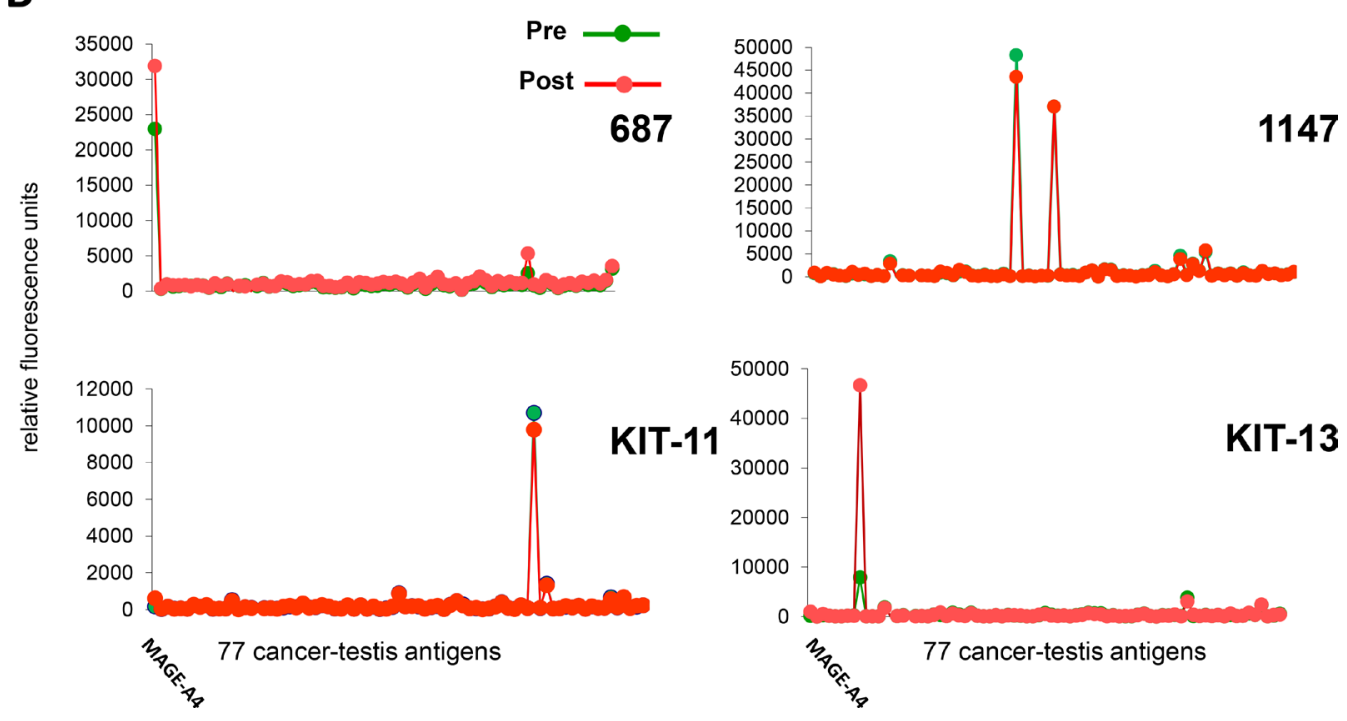

Figure 5: Array profiling assay. ProtoArray was performed using 1:500 diluted serum from 7 patients who received 4 or more vaccinations with CHP-MAGE-A4. The X-axis shows 77 cancer-testis antigens, including MAGE-A4. Responses occurred to the same antigens in pre-vaccine and post-vaccine sera, with varying intensities. In the X-axis, the 77 antigens were listed in the same order as those in Table 4, from the top of the left column to the bottom of the right column. (A) Three patients, 887, KIT-5, and KIT-8, were vaccinated with $100 \mu \mathrm{g}$ of CHP-MAGE-A4. (B) Four patients, 687, KIT-11, 1147, and KIT-13, were vaccinated with $300 \mu \mathrm{g}$ of CHP-MAGE-A4. 
melanoma antigen family A, 4 (MAGEA4), transcript variant 2 acrosin binding protein (ACRBP)

melanoma-associated antigen 2

ankyrin repeat domain 45 (ANKRD45)

transmembrane protein with EGF-like and two follistatin-like domains 1 (TMEFF1)

cell differentiation protein RCD1 homolog

melanoma antigen family B, 2 (MAGEB2)

PDZ binding kinase (PBK)

DEAD (Asp-Glu-Ala-Asp) box polypeptide 43 (DDX43)

PAS domain containing 1 (PASD1)

synaptonemal complex central element protein 1 (SYCE1)

B melanoma antigen 3

maelstrom homolog (Drosophila) (MAEL)

outer dense fiber of sperm tails 3 (ODF3)

G patch domain containing 2 (GPATCH2)

PDZ binding kinase (PBK)

G antigen 1 (GAGE1)

Melanoma-associated antigen B3

heat shock protein, alpha-crystallin-related, B9 (HSPB9)

ADAM metallopeptidase domain 2 (fertilin beta) (ADAM2)

cancer/testis antigen family 45, member A1 (CT45A1), mRNA.

melanoma antigen family A, 12 (MAGEA12)

testis-specific serine kinase 6 (TSSK6)

chondrosarcoma associated gene 1 (CSAG1)

LEM domain-containing protein 1

lactate dehydrogenase $\mathrm{C}$ (LDHC), transcript variant 1

TTK protein kinase (TTK)

LEM domain-containing protein 1

Sperm surface protein Sp17

preferentially expressed antigen in melanoma (PRAME) synovial sarcoma, $\mathrm{X}$ breakpoint 4, mRNA (cDNA

clone MGC:119056 IMAGE:40003338), complete cds

chromosome X open reading frame 48 (CXorf48)

family with sequence similarity 46 , member D

(FAM46D)

transmembrane phosphatase with tensin homology (TPTE)

coiled-coil domain containing 33 (CCDC33), transcript variant 1

SPANX family, member C (SPANXC)

$\mathrm{P}$ antigen family, member 2 (prostate associated)

(PAGE2)

SPANX family, member E (SPANXE)

outer dense fiber of sperm tails 2 (ODF2), transcript variant 1

testis specific, 10 (TSGA10)

SPANX family, member N3 (SPANXN3)

testis expressed 101 (TEX101)

$\mathrm{P}$ antigen family, member 5 (prostate associated) (PAGE5)

zinc finger protein 165 (ZNF165)

chromosome X open reading frame 48 (CXorf48), transcript variant 2

outer dense fiber of sperm tails 2 (ODF2)

POTE ankyrin domain family, member B, mRNA (cDNA clone MGC:119373 IMAGE:40006489), complete cds

Down syndrome critical region protein 8

cytochrome c oxidase subunit VIb polypeptide 2 (testis) (COX6B2)

nucleolar protein 4, mRNA (cDNA clone MGC:8430

IMAGE:2821116), complete cds

synaptonemal complex central element protein 1

(SYCE1), transcript variant 2

$\mathrm{P}$ antigen family, member 1 (prostate associated)

(PAGE1)

Dual specificity protein kinase TTK

Melanoma-associated antigen 3

nuclear RNA export factor 2 (NXF2), transcript

variant 1

melanoma antigen family B, 4 (MAGEB4)

Protein FAM133A

CPX chromosome region, candidate 1 (CPXCR1)

spermatogenesis associated 19 (SPATA19)

Melanoma-associated antigen 2 
Sperm protein associated with the nucleus on the $\mathrm{X}$ chromosome N4

calreticulin 3 (CALR3)

melanoma antigen family A, 10 (MAGEA10), transcript variant 2

$\mathrm{P}$ antigen family, member 5 (prostate associated) (PAGE5), transcript variant 1

$\mathrm{X}$ antigen family, member 2 (XAGE2)

PDZ binding kinase (PBK)

centrosomal protein 290kDa (CEP290)

outer dense fiber of sperm tails 4 (ODF4)

SPANX family, member B1 (SPANXB1) synovial sarcoma, X breakpoint 5 (SSX5)

sperm associated antigen 9 (SPAG9)

synovial sarcoma, X breakpoint 3 (SSX3), transcript

variant 1

tubby like protein 2 (TULP2)

TTK protein kinase (TTK)

interleukin 13 receptor, alpha 2 (IL13RA2)

melanoma antigen family B, 1 (MAGEB1), transcript

variant 1

Sperm protein associated with the nucleus on the $\mathrm{X}$ chromosome D

77 antigens were listed in the same order as Figure 5, from the left to the right in the X-axis.

Three patients in each trial were given $100 \mu \mathrm{g}$ of CHP-MAGE-A4 every 2 weeks. If there were no adverse events greater than grade 2 , the next 3 patients in each trial were immunized with $300 \mu \mathrm{g}$ of CHP-MAGE-A4 every 2 weeks. If there were no adverse events greater than grade 2, more patients were enrolled into the $300 \mu \mathrm{g}$ CHP-MAGE-A4 cohort in the trial at Mie University and Nagasaki Medical Center, and into the $300 \mu \mathrm{g}$ CHP-MAGE-A4 plus immunoadjuvant, OK-432 (Chugai Pharmaceutical Co Ltd, Tokyo, Japan) cohort in the trial at Kitano Hospital. OK-432 is a penicillinkilled and lyophilized preparation of a low-virulence strain of Streptococcus pyogenes (group A). It works as an immune-modulator, and was reported to stimulate toll-like receptor (TLR)-4 and to activate antigenpresenting cells [16]. Clinical responses were assessed according to the Response Evaluation Criteria in Solid Tumors (RECIST) ver 1.1. Each patient received 6 doses of the CHP-MAGE-A4 vaccine. Patients could receive additional treatments if they wished, as long as they had a PS of 2 or less. Safety was evaluated according to the National Cancer Institute Common Terminology Criteria for Adverse Events (CTCAE) ver 3.0. All the safety information was collected and evaluated, and the dose escalation was judged by the independent Data and Safety Committee.

The study was performed in accordance with the current version of the Declaration of Helsinki. Each protocol was approved by the Human Ethics Committee at each hospital. Written informed consent was obtained from each patient enrolled in the trials. Clinical trials conducted at Mie University Hospital/Nagasaki Medical Center and Kitano Hospital were registered in the UMIN Clinical Trials Registry as UMIN000001599 and UMIN000002153, started on December 25, 2008 and July 2, 2009, and ended on November 23, 2012 and July 31, 2014 , respectively.

\section{Expression of MAGE-A4 and NY-ESO-1 antigen in tumor tissues}

MAGE-A4 expression was assessed by immunohistochemistry (IHC) using the monoclonal antibodies 57B, MCV-1, and MCV-4, as previously described [17], or by quantitative real-time PCR (qRTPCR) using specific primers [18]. NY-ESO-1 expression was assessed by immunohistochemistry with the monoclonal antibody E978 (Sigma-Aldrich, Saint Louis, MO) [19], or quantitative qRT-PCR using specific primers [18]. Tissue samples with a $5 \%$ or higher positively stained area were judged as antigen positive. Focally stained samples were also positive. Tumor samples expressing 12.2 or more PCR-amplified copies were judged as MAGE-A4 positive. Tumor samples also expressing 1.0 or more PCR-amplified copies were judged as NY-ESO-1 positive.

\section{Serum samples}

To analyze antigen-specific antibody responses, sera were collected at baseline and at 2 weeks after each vaccination. All sera were stored at $-80^{\circ} \mathrm{C}$ until analysis.

\section{Antibody responses to MAGE-A4 and NY-ESO-1 antigens}

Specific antibodies to MAGE-A4 and NYESO-1 antigens in the sera were measured by ELISA as described previously [20]. Briefly, recombinant MAGE-A4 and NY-ESO-1 proteins (GST-tag) were absorbed onto immunoplates (442404; Nunc, Roskilde, Denmark) at a concentration of $10 \mathrm{ng} / 50 \mu \mathrm{L} /$ well at $4^{\circ} \mathrm{C}$. The collected serum samples were diluted from 1:400 to 4 times dilution. After washing and blocking the plate, the sera were added and incubated for $10 \mathrm{~h}$. After washing, 
goat anti-human $\operatorname{IgG}(\mathrm{H}+\mathrm{L}$ chain) (MBL, Nagoya, Japan) conjugated with peroxidase (The Binding Site, San Diego, CA) was added. After addition of tetramethyl benzidine substrate (Pierce, Rockford, IL), the plate was read using a Microplate Reader (model 550; Bio-Rad, Hercules, CA).

Serum samples from healthy volunteers were evaluated to determine a cut-off level for the antiMAGE-A4 and anti-NY-ESO-1 antibodies based on the $\mathrm{OD}_{450-550}$ absorption value. Serum samples from 20 healthy volunteers were obtained, and assayed in ELISA for MAGE-A4 and NY-ESO-1 IgG antibodies. The cutoff level for each IgG was defined as each mean $\mathrm{OD}_{450-550}$ absorption value $+1.65 \times$ standard deviation $(\mathrm{SD})$ value. The cut-off level of anti-MAGE-A4 and anti-NY-ESO-1 $\operatorname{IgG}$ were 0.32 and 0.27 , respectively. A sample was considered to be positive for anti-MAGE-A4 and antiNY-ESO-1 antibodies if the optical density (OD) ${ }_{450-550}$ absorption value on ELISA was at the cut-off level or higher at a serum dilution of 1:400. The immune responses of patients with pre-existing anti-MAGE-A4 or anti-NY-ESO-1 antibodies were judged as showing augmentation if the OD values increased by 2 -fold or greater.

\section{Seromics: array profiling assay}

ProtoArray microarrays (v4.0; Invitrogen) were purchased and used according to the manufacturer's instructions. Briefly, after blocking for $1 \mathrm{~h}$ at $4^{\circ} \mathrm{C}$ and washing, arrays were incubated in Quadriperm dishes (Greiner Bio One) placed on a horizontal shaker (50 rpm) for $90 \mathrm{~min}$ at $4^{\circ} \mathrm{C}$ with individual sera diluted 1:500 in $5 \mathrm{ml}$ washing buffer $(0.1 \%$ Tween 20 [vol/vol], 1\% BSA [wt $/ \mathrm{vol}]$ in PBS). After washing, binding of $\operatorname{IgG}$ was detected by incubation with Alexa Fluor 647 goat antihuman IgG (Invitrogen) diluted 1:2,000 in assay buffer for $90 \mathrm{~min}$ at $4^{\circ} \mathrm{C}$. Arrays were washed again and dried by centrifugation. Arrays were scanned at $10-\mu \mathrm{m}$ resolution using a microarray scanner (Axon 4200AL with GenePix Pro Software; Molecular Devices), and fluorescence was detected according to the manufacturer's instructions. Images were saved as 16-bit TIFF files and analysis was performed using GenePix. The median net intensity in relative fluorescence units (rfu) was reported for each spot. Out of 9,481 antigens, 77 cancer-testis antigens were selected and analyzed for pre- and post-vaccine expression in the sera (Table 4).

\section{Statistical analyses}

All analyses were performed using GraphPad Prism ver.6.00 for Mac (GraphPad Software, CA, USA). The probability of survival was calculated by the KaplanMeier method, and statistical differences were evaluated by the log-rank test.

\section{Abbreviations}

CHP: cholesteryl pullulan; MAGE: melanomaassociated antigen; MHC: major histocompatibility antigen complex; SD: stable disease; PD: progressive disease; OD; optical density; ELISA: enzyme-linked immunosorbent assay; cDNA: complementary DNA; PS: performance status; HIV: human immunodeficiency virus; RECIST: response evaluation criteria in solid tumors; CTCAE: common terminology criteria for adverse events; PCR: polymerase chain reaction; IgG: immunoglobulin G; BSA: bovine serum albumin; PBS: phosphate buffered saline; GST: glutathione S-transferase; SD: standard deviation.

\section{Author contributions}

SU conducted the clinical trial as a principal investigator at Kitano Hospital, collected the clinical samples, interpreted the data, and wrote the manuscript. YM supervised all the analysis of immune reactions, and interpreted the data. YN conducted the clinical trial at Nagasaki Medical Center, collected the clinical samples, interpreted the data, and contributed to the statistical analysis. ES and TS performed pathological evaluations of tumor-antigen expressions. NH contributed to supervision of the investigational drug preparation. HI produced the monoclonal antibodies for MAGE-A4 antigen detection. HS oversaw the study design and data interpretation. SK conducted the clinical trial as a principal investigator at Mie University, collected the clinical samples, interpreted the data, and wrote the manuscript.

\section{ACKNOWLEDGMENTS}

We thank all co-workers from all units of Kitano Hospital, Mie University Hospital, and Nagasaki Medical Center for their skillful assistance in this study, and for the support they provided to the patients under their care. We express thanks to Ms. Sahoko Sugino and Ms. Junko Nakamura (Mie University) for providing technical assistance in the ELISA and Seromics assays. We are also grateful to Dr. Tadashi Hishida at ImmunoFrontier Inc. for providing the CHP-MAGE-A4 vaccine.

\section{CONFLICTS OF INTEREST}

HS is a stockholder of ImmunoFrontier, Inc. The other authors have no conflicts of interest to declare.

\section{FUNDING}

This work was supported by a Grant-in-Aid for Scientific Research (KAKENHI) from the Japan Society 
for the Promotion of Science, Grant Number 15K10093 and $16 \mathrm{~K} 07168$.

\section{REFERENCES}

1. Ikuta Y, Katayama N, Wang L, Okugawa T, Takahashi Y, Schmitt M, Gu X, Watanabe M, Akiyoshi K, Nakamura H, Kuribayashi K, Sunamoto J, Shiku H. Presentation of a major histocompatibility complex class 1-binding peptide by monocyte-derived dendritic cells incorporating hydrophobized polysaccharide-truncated HER2 protein complex: implications for a polyvalent immuno-cell therapy. Blood. 2002; 99:3717-24. https://doi.org/10.1182/ blood.V99.10.3717.

2. Kitano S, Kageyama S, Nagata Y, Miyahara Y, Hiasa A, Naota H, Okumura S, Imai H, Shiraishi T, Masuya M, Nishikawa M, Sunamoto J, Akiyoshi K, et al. HER2specific T-cell immune responses in patients vaccinated with truncated HER2 protein complexed with nanogels of cholesteryl pullulan. Clin Cancer Res. 2006; 12:7397-405. https://doi.org/10.1158/1078-0432.CCR-06-1546.

3. Kawabata R, Wada H, Isobe M, Saika T, Sato S, Uenaka A, Miyata H, Yasuda T, Doki Y, Noguchi Y, Kumon H, Tsuji $\mathrm{K}$, Iwatsuki K, et al. Antibody response against NY-ESO-1 in CHP-NY-ESO-1 vaccinated patients. Int J Cancer. 2007; 120:2178-84. https://doi.org/10.1002/ijc.22583.

4. Aoki M, Ueda S, Nishikawa H, Kitano S, Hirayama M, Ikeda H, Toyoda H, Tanaka K, Kanai M, Takabayashi A, Imai H, Shiraishi T, Sato E, et al. Antibody responses against NY-ESO-1 and HER2 antigens in patients vaccinated with combinations of cholesteryl pullulan (CHP)-NY-ESO-1 and CHP-HER2 with OK-432. Vaccine. 2009; 27:6854-61. https://doi.org/10.1016/j.vaccine.2009.09.018.

5. Haier J, Owzcareck M, Guller U, Spagnoli GC, Bürger H, Senninger N, Kocher T. Expression of MAGE-A cancer/ testis antigens in esophageal squamous cell carcinomas. Anticancer Res. 2006; 26:2281-7. https://doi.org/10.1002/ hed.20380.

6. Akcakanat A, Kanda T, Tanabe T, Komukai S, Yajima K, Nakagawa S, Ohashi M, Hatakeyama K. Heterogeneous expression of GAGE, NY-ESO-1, MAGE-A and SSX proteins in esophageal cancer: Implications for immunotherapy. Int J Cancer. 2006; 118:123-8. https://doi. org/10.1002/ijc.21219.

7. Kageyama S, Wada H, Muro K, Niwa Y, Ueda S, Miyata H, Takiguchi S, Sugino SH, Miyahara Y, Ikeda H, Imai N, Sato E, Yamada T, et al. Dose-dependent effects of NY-ESO-1 protein vaccine complexed with cholesteryl pullulan (CHPNY-ESO-1) on immune responses and survival benefits of esophageal cancer patients. J Transl Med. 2013; 11:246. https://doi.org/10.1186/1479-5876-11-246.

8. Oshima Y, Shimada H, Yajima S, Nanami T, Matsushita K, Nomura F, Kainuma O, Takiguchi N, Soda H, Ueda T, Iizasa T, Yamamoto N, Yamamoto H, et al. NY-ESO-1 autoantibody as a tumor-specific biomarker for esophageal cancer: screening in 1969 patients with various cancers. J Gastroenterol. 2016; 51:30-4. https://doi.org/10.1007/ s00535-015-1078-8.

9. Kawada J, Wada H, Isobe M, Gnjatic S, Nishikawa H, Jungbluth AA, Okazaki N, Uenaka A, Nakamura Y, Fujiwara S, Mizuno N, Saika T, Ritter E, et al. Heteroclitic serological response in esophageal and prostate cancer patients after NY-ESO-1 protein vaccination. Int J Cancer. 2012; 130:584-92. https://doi.org/10.1002/ijc.26074.

10. Corbière V, Chapiro J, Stroobant V, Ma W, Lurquin C, Lethé B, Van Baren N, Van Den Eynde BJ, Boon T, Coulie PG. Antigen spreading contributes to MAGE vaccinationinduced regression of melanoma metastases. Cancer Res. 2011; 71:1253-62. https://doi.org/10.1158/0008-5472. CAN-10-2693.

11. Fujiwara S, Wada H, Kawada J, Kawabata R, Takahashi T, Fujita J, Hirao T, Shibata K, Makari Y, Iijima S, Nishikawa H, Jungbluth AA, Nakamura Y, et al. NY-ESO-1 antibody as a novel tumour marker of gastric cancer. Br J Cancer. 2013; 108:1119-25. https://doi.org/10.1038/bjc.2013.51.

12. Fujita S, Wada H, Jungbluth AA, Sato S, Nakata T, Noguchi Y, Doki Y, Yasui M, Sugita Y, Yasuda T, Yano M, Ono T, Chen YT, et al. NY-ESO-1 expression and immunogenicity in esophageal cancer. Clin Cancer Res. 2004; 10:6551-8. https://doi.org/10.1158/1078-0432.CCR-04-0819.

13. Szender JB, Papanicolau-Sengos A, Eng KH, Miliotto AJ, Lugade AA, Gnjatic S, Matsuzaki J, Morrison CD, Odunsi K. NY-ESO-1 expression predicts an aggressive phenotype of ovarian cancer. Gynecol Oncol. 2017; 145:420-5. https:// doi.org/10.1016/j.ygyno.2017.03.509.

14. Saito T, Wada H, Yamasaki M, Miyata H, Nishikawa H, Sato E, Kageyama S, Shiku H, Mori M, Doki Y. High expression of MAGE-A4 and MHC class I antigens in tumor cells and induction of MAGE-A4 immune responses are prognostic markers of CHP-MAGE-A4 cancer vaccine. Vaccine. 2014; 32:5901-7. https://doi.org/10.1016/j.vaccine.2014.09.002.

15. Miyauchi K, Tsuchikawa T, Wada M, Abiko T, Kyogoku N, Shichinohe T, Miyahara Y, Kageyama S, Ikeda H, Shiku H, Hirano S. Clinical relevance of antigen spreading pattern induced by CHP-MAGE-A4 cancer vaccination. Immunotherapy. 2016; 8:527-40. https://doi.org/10.2217/ imt-2016-0007.

16. Okamoto M, Furuichi S, Nishioka Y, Oshikawa T, Tano T, Ahmed SU, Takeda K, Akira S, Ryoma Y, Moriya Y, Saito M, Sone S, Sato M. Expression of toll-like receptor 4 on dendritic cells is significant for anticancer effect of dendritic cell-based immunotherapy in combination with an active component of OK-432, a streptococcal preparation. Cancer Res. 2004; 64:5461-70. https://doi.org/10.1158/0008-5472. CAN-03-4005.

17. Kageyama S, Ikeda H, Miyahara Y, Imai N, Ishihara M, Saito K, Sugino S, Ueda S, Ishikawa T, Kokura S, Naota $\mathrm{H}$, Ohishi K, Shiraishi T, et al. Adoptive transfer of MAGE-A4 T-cell receptor gene-transduced lymphocytes in patients with recurrent esophageal cancer. Clin Cancer 
Res. 2015; 21:2268-77. https://doi.org/10.1158/1078-0432. CCR-14-1559.

18. Soga N, Hori Y, Yamakado K, Ikeda H, Imai N, Kageyama S, Nakase K, Yuta A, Hayashi N, Shiku H, Sugimura Y. Limited expression of cancer-testis antigens in renal cell carcinoma patients. Mol Clin Oncol. 2013; 1:326-30. https://doi.org/10.3892/mco.2012.40.

19. Jungbluth AA, Chen YT, Stockert E, Busam KJ, Kolb D, Iversen K, Coplan K, Williamson B, Altorki N, Old LJ. Immunohistochemical analysis of NY-ESO-1 antigen expression in normal and malignant human tissues. Int $\mathrm{J}$ Cancer. 2001; 92:856-60. https://doi.org/10.1002/ijc.1282.

20. Stockert E, Jäger E, Chen YT, Scanlan MJ, Gout I, Karbach J, Arand M, Knuth A, Old LJ. A Survey of the humoral immune response of cancer patients to a panel of human tumor antigens. J Exp Med. 1998; 187:1349-54. https://doi. org/10.1084/jem.187.8.1349. 